\title{
Experiences from families of children with cerebral paralysis in context of social vulnerability
}

\author{
Marja Rany Rigotti Baltor ${ }^{1}$ \\ Giselle Dupas ${ }^{2}$
}

Objective: to describe and to analyze the experience from families of children with cerebral paralysis living under circumstances of social vulnerability. Method: six resident families in area with this characteristic were interviewed. It was opted to use the Symbolic Interactionism as theoretic reference and the Thematic Content Analysis of Bardin as analysis method for the data. Result: the experience of such families is represented in the subjects: Reorganizing the Life, with the categories "Discovering the way" and "Accommodating the routine", and Stopping a Constant Fight with the categories: "Primary Carer being overcharged", "Coexisting with the preconception", "Having locomotion difficulty" and "Living with financial difficulties". Conclusion: the social vulnerability influences how the family bears the chronic condition. Professionals and strategies of public health are a power to minimize impacts including those related to the family budget, but they have not been effective. They need to be sensitized to become supporting resources, to offer and to guide the access to the support networks and to spur the social service in action when necessary. This study adds knowledge to the already existing by pointing out peculiarities of the family experience in situations regarding two variables of difficult handling: chronicity and social vulnerability, evidencing the role of the professional in search of the solution for the confrontation of demands and sufferings together with the family.

Descriptors: Poverty; Child; Cerebral Palsy; Family; Nursing.

\footnotetext{
${ }^{1}$ Master's student, Departamento de Enfermagem, Universidade Federal de São Carlos, São Carlos, SP, Brazil ${ }^{2}$ PhD, Professor, Departamento de Enfermagem, Universidade Federal de São Carlos, São Carlos, SP, Brazil.
} 


\section{Introduction}

The cerebral paralysis is a condition caused by the damage or bad formation of the brain, mainly resulting from prematurity and adverse intercurrence at the time of childbirth. It causes functional limitations, which impact the motor, intellectual and behavioral abilities of the affected individual ${ }^{(1-2)}$. International literature registers that the prevalence rate of this condition is 2 to 2.5 per 1,000 births $^{(3)}$ and the life expectancy is 20 years $^{(4)}$. In underdeveloped countries the incidence of this condition is superior, being 7 cases per 1,000 births. Official national data on this incidence were not found, but the estimation is at about 30,000 to 40,000 new cases per year(5). Through characteristics like long duration, recurrent, establishing continuous dependence, being incurable, irreversible and degenerative, such condition is considered chronic ${ }^{(6)}$. Specifically in infancy, the chronic condition imposes modifications in life and limits the participation of the child in activities which are normal for its age, and it also restricts it in playing ${ }^{(7-8)}$. Families who have a child in a chronic condition of the illness are financially more vulnerable since the expenses are three times higher than with healthy children. Such picture is verified because beyond the involved costs for materials regarding support, transport and therapy, the deriving demands of the chronic condition interfere with the capacity of the parents to keep the job(9).

The socio-economic status is a determinative factor for the health situation, being the poverty imposes the worst life conditions on the child in a complex chronic condition $^{(10)}$. The environment is considered a promoter for negative deployment of the illness, since the circumstances under which the family lives reflects in its psychological and physical conditions, beyond restricting the access to treatment ${ }^{(11-12)}$.

In Brazil, the inequality in the income distribution and raised levels of social vulnerability intervenes in the access to health. The 2010 census discloses that $8.5 \%$ of the Brazilians live in condition of extreme poverty (per capita income below R\$70 per month), amongst which $17 \%$ are concentrated in the southeast of the country ${ }^{(13)}$. Understanding the context and the impact that the economic conditions have on the health of the population, as well as its strategies of confrontation, can put the professional performance in the direction to establish care partnerships, increase the conquests and jointly establish goals to be reached.

Based on the above considerations, the objective of this study was to describe and to analyze the experience of families in a situation of social vulnerability who have children with cerebral paralysis. It was pursued to promote the reflection on the theme from the family perspective, with the view to perceive in which means the situation of social vulnerability influences and interferes in the life with the chronic condition.

\section{Method}

This article derives from the analysis of results of the Master dissertation "Chronic Illness in infancy in the context of social vulnerability: the experience of the family", whose development was approved by the Ethics Committee of the higher education institution to which the post-graduation program is connected, having observed all the recommendations of resolution 196/96.

The study was developed in a city in the interior of the state São Paulo, in districts with São Paulo Social Vulnerability Index (IPVS) below 5 . This index is composed by income indicators, schooling, family life cycle and space segregation. It also considers that the place of residence influences the life conditions of the individual due to the possibility or difficulty of access to assets and as well public and private services. Thus, by means of tax sectors, areas according to vulnerability degrees can be mapped. Degree five is attributed to the regions that have the worst conditions in the socioeconomic dimension, being the maximum index of social vulnerability found in the city of the study. The purpose of such indicator is to measure public policies regarding confrontation of this situation(14).

A listing with the addresses of 20 families who lived in a situation of social vulnerability 5 and had in their composition a child with cerebral paralysis was supplied by the city. By means of the listed addresses, the researcher visited the residences to present the research and to invite the families to participate at a later date in accordance with the preference of the family members. In case contact could not be established at the domicile, two new attempts were made before discarding the address. From the listed families, six accepted to participate in the present research.

For the researched data to learn about the family experience the theoretic reference for the Symbolic Interactionism was chosen, that conceives the human being as active, who interacts in the social context and attributes meanings through relations, what reverberates in the respective behavior. This process determines in cyclical form the interaction of the person with others and oneself(15). 
Holding the interview in semi-directed form allows the researcher the immediate understanding of the information, clarification of dubious questions and adequacies in the course of the interview ${ }^{(16)}$. In the light of such knowledge, the families were enticed to discourse on their experiences through the leading question: "How has it been for you to live with the illness of (name of the child) day by day?". The interviews were recorded, transcribed in completeness and systemized according to the Thematic Analysis of Content method proposed by Bardin(17).

This method consists of a set of techniques used for the understanding of the implicit meanings in the messages. The analysis preconizes the following stages: that the transcription of the interviews, made in completeness, is conducted in detail and depth to apprehend how the family lives this experience. This phase is named pre-analysis. The following readings have the purpose of better exploring the material that passes the process of detachment and regrouping, called data systematization. Afterwards, the data that had initially been separated by subjects are reread whose process of reflection and analysis of the results produces the interpretation of those ${ }^{(17)}$.

\section{Results}

Two subjects were identified that were brought up regarding the family experience of living in a situation of social vulnerability and having a child with cerebral paralysis. The subject Reorganizing the Life aggregates the categories: "Discovering the way" and "Accommodating the routine", whereas Stopping a Constant Fight accumulates the categories: "Primary Carer being overcharged", "Coexisting with the preconception", "Having locomotion difficulty" and "Living with financial difficulties". Below we present each one of them, and to elucidate the categories, stretches of the interviews with the participants were selected, identifying the kinship with the child, number of the interview and the document where the excerpt is to be found.

\section{Reorganizing the Life}

In relation to this subject, it can be verified that when receiving the diagnosis that the child has cerebral paralysis, the family suffers a proportionally great impact of the loss and fight of the idealized son and for the necessity of entering a world of unknown demands. The future becomes uncertain as the universe of the chronic condition was not part of the family perspectives. Through being unaware of the care strategies for this child, the family faces difficulties and therefore perceives itself in a movement of discovering ways to be able to continue.

The new necessities inserted in the daily family life promote the reorganization of the relations, of the routines of each member, as well as of the family routine, once the dependence of the child demands integral devotion of one of the spouses, what restricts the possibility of insertion of one of them in the working world and consequently in the family income. The family needs to accommodate the routine as to organize themselves and to be able to meet the care necessities of the child.

\section{Uncovering the way}

The condition of the child is initially unknown by the family who starts to perceive different behaviors as expected from a healthy child in the day by day and, from then on, is in search of understanding the picture:

We only perceived it in the course of time! As he did not crawl, he did not keep upright! There we perceived that he was a different child. (Sister, E1, P.5)

The sense of helplessness and the lack of commitment of the health professionals with the experienced situation make the family search answers on their own initiative. The picture of the child starts to be uncovered from fragmented information that the family receives from diverse professionals besides by means of relation with mothers who experience similar situations to the one of the child and who tell how their way had been. The lack of specific orientation generates unease in the care offered to the child and the family starts to reflect on the effectiveness of the given assistance:

Nobody told me! They were born prematurely and left the hospital. Suddenly I perceived that something had gone wrong and the doctor ordered me to make physiotherapy. There they told me that there were nine months of physiotherapy. And those nine months had already passed. So I asked physiotherapist at that time, "Weren't it only nine months? But those nine months have already passed". And she said "No, it might be 1 year, 2, 10, 30 years!" and we have been making physiotherapy until today! (Mother, E2, P.1)

When the diagnosis is finally received, the family not always accepts it, not conforming to a future of restrictions and impossibilities, but longing for the improvement of the child. The care is integrated in the routine, ignoring the pessimistic forecasts, always in search of the best development of the child: 
No matter how hard the almost two months he stayed in the ICU had been, I thought that when he came back home and took medicines, he would get better. And until I understood that it was not like that (pause) it was very difficult! After talking about cerebral paralysis I started to do this and that! [...] one says one thing and the other one says another thing and we start to internalize it in our heads and go ahead in life! (Mother, E5, P.2)

The family thinks about the consequences that the neuromotor alteration causes, comparing it with other children, and suffers when thinking about the future their child is destined for:

You see the others growing up evolving and him not! So, for us it is difficult, very difficult! (Father, E1, P.2)

But my father doesn't accept it! He (father) sees all (other children) running and playing. And he (child) was supposed to be normal! (Sister, E1, P.6)

\section{Accommodating the routine}

Over the time, the family starts to recognize the signals and symptoms shown by the child and is able to develop care strategies, relating the necessities in better forms to meet the demands. What in principle was faced with difficulty passes to be added naturally to the family routine, being carried out in a more secure form:

If he has a little crises today I already know! At the beginning I was scared, desperate, my wish was to catch him and take him to hospital! [...] I was desperate! Not today [...] I already understand that it is part, that he has his phases! So I am already more experienced! Experience in taking care of him. (Mother, E5, P.3)

The family members associate what they experience in the daily life to what they observe in the practice of the professionals, thus developing their own way to taking care. This is the strategy of the carer, not to depend exclusively on the health service, what is told with pride and satisfaction for the reach of autonomy:

I was quite worried if I would be capable of taking care of him. After I started going to the services and made many friendships in these places, I was developing and I started to learn. Today I can already say that I am a whiz in the care of him! (Mother, E5, P.1)

The family feels gratified when observing that, in spite of the imposed difficulties, it can reorganize itself and create strategies, having the care of the child under control:

At the beginning it was horrible! I entered a world I wasn't part of. I didn't even know what cerebral paralysis was. Today I know more. Not that I am an expert but I already know a little more! We move on adapting to the things that appear and will be learning. [...] I myself do it; I don't depend on the hospital anymore. (Mother, E2, P.1/6)

The family lives together and participates in the process of reached conquests. It perceives the advances and the progress that the child accomplishes, as smaller and slower they might be, feeling rewarded for the effort and persistence.

Every time he smiles, we see that he is improving, so for us it is a joy! (Sister, E1, P.6)

I believe that it is good for him! At least he is not atrophying! But walking, what is the dream we have, and speaking, that is alone for God! But only he not to atrophy is already great! I don't know, I accept him so well that for me this is a detail! (Mother, E4, P.2)

He was hard, hard, hard! You took him and he stayed all hard! And today not anymore, he already moves a lot! (Mother, E5, P.6)

The way is marked by the constant family pursuit for aids guaranteed by the Brazilian legislation. The family faces tiring bureaucratic processes whose delay does not respect the pressing necessities, once the children continue to grow and develop, demanding quick decision taking and adoption of measures to prevent greater physical and mental consequences:

[...] if I know that he (the child) has the right, I go for it! I make it valid! (Mother, E4, P.10)

\section{Stopping a constant fight}

The chronic condition of the child's illness demands continuous care and the family get organized to meet such necessities. Associated to this process it is the own family dynamic and the individual necessities of the members, what in general makes for the main carer is overcharged oneself. The daily life is characterized by a continuous movement to bypass difficulties in order to be able to take care of the child, distinctively related those with locomotion of the child from one attendance to another. Amidst all this the family still has to deal with the situations of preconception that deplete and sadden it. The central point of the difficulties of this family experience is the experience of financial difficulties that portrays the social vulnerability of the families participating in the research, emphasizing its influence on the daily to day of the family and professional care of children with cerebral paralysis.

\section{Primary Carer being overcharged}

The mother, as primary carer, centralizes beyond the domestic activities the assistance to the child. It is hard to be able to carry out any kind of activity without 
the child being present for not being able to count on the aid of another person to divide the care. The lack of time to carry out other tasks results in isolating the carer from social activities and leisure. When thinking about the future she suffers because she perceives the dependence of the child and does not see a reliable person on whom she can count in her absence. Beyond the psychic suffering, there is also the physical overload. The daily activities become more difficult with the growth of the child and, as its necessities are put first place, the carer hardly finds time to take care of oneself. It is a way marked as solitary and demanding:

[...] I have a problem with my back. Last week I went to the doctor and I was with him (the child) because I had nobody with whom I could leave him! [...] It was even good because I showed the doctor. He said that I had attrition in the back, he prescribed me a medication and talked about physiotherapy. He said that I couldn't carry weight! Then I showed him (the child) and said: "this here I cannot avoid! This here is my every day routine!" Because my husband is out of home all day! (Mother, E5, P.9)

$\mathrm{He}$ (the child) doesn't stay with anybody [...] if I have to do something he has to go together with me (Father, E3, P.3)

And as it's only me taking care of him, in this raising and seating, I have attrition in the back! (Mother, E5, P2)

And if I wasn't here tomorrow or later? How will it be? My goodness! I don't like to even think about it! (Mother, E5, P.9).

\section{Coexisting with the preconception}

To this way, already characterized by so many difficulties, comes another one that submits the family to a different strain, the preconception. It says that such attitudes occur because there is a lack of sensitivity, unconsciousness of the experienced situation and, in consequence, disdain for the difficulties and limitations that the child and the family face. Striving for the understanding of the peculiarities of the situation and trying to not suffer, but it cannot always be achieved:

Nobody of the family visits, nobody does anything! It seems that he is a little monster! My mother-in-law took him like this (she makes the gesture of holding far from the body) (Mother, E4, P.3).

\section{Having locomotion difficulty}

As the child grows, the obstacles related to locomotion increase since the public transport and the access courses do not meet the necessities of the people with special requirements. To have access to special transport, supplied by the City Government, the family faces a bureaucratic process of difficult admission, and when obtaining, it proves to be inflexible to meet the demands of the family. Streets and establishments are not adapted to the needs of the wheelchair user. When imagining all the difficulties to be faced, the families prevent to leave with the child, but the therapeutical routine implies journeys and continuous health treatments:

There are a lot of ramps to go up and down! I go there with the transport, but there it's me who carries. And that with my age (pause)! Age comes to him and it also comes to the mother! [...] It is horrible to walk with him on the sidewalk! Everything is broken, full of holes! In the city, there are stores that have a ramp to go up and there are stores that don't! It is difficult! Who's going to fix this? The City Government does nothing! (Mother, E4, P.7/11).

[...] the buggy is very big (to go by bus). It even works, in those special buses, but they almost don't exist. So she (the mother) takes him on the lap. (Father, E3, P.3)

The mobility inside the residence also becomes arduous. The families talk about the desire to adapt the homes in a way to make this process less tiring and more practical. Although being a great desire, they ponder the involved cost in these reforms and the health necessities are listed as priority in the budgetary planning:

He has a wheelchair [...] but the problem is that he grows very much [...]. Also I take him on the lap [...] but it is difficult to carry him, he is big! [...] I want to adapt the house! We are trying to adapt the corridor by filling it with earth there in the front to be able to make a ramp to be better! Because in this form it is complicated. And I would also like to build another bathroom, already suitable! Because I have to be carrying him on the arms! Why do you think that I am like this? (she refers to the pain in the back) (Mother, E2, P.7/8).

\section{Living with financial difficulties}

The financial component plays a basic role in the care. In condition of social vulnerability, it affects the family dynamics, it compels to learn to manage the money and to list the main necessities:

If there was more money it would be great! [...] We do it like this, we arrange what is causing problems and if there is money left, we see what we can do! (Mother, E5, P.12)

Without money it is difficult! It needs money to do the things! [...] The expenses are big! Only the diapers... on the trips (treatments) one always has to have money to eat out! And we have here the difficulty to not have it here! To be outside and not having 1 Real to drink some water [...] It is horrible to not have the money! At times I took some milk along and when I arrived there the milk had turned sour. So I didn't eat all day. It is difficult, I passed difficult situations! (Mother, E2, P.7) 
I am only waiting. She (the social assistant) told me that it is only to approve the amount of money that they make the orthosis. And she is there waiting. For me it is tiring. I went there to see if I could buy it, but it was $R \$ 800$. And there were $R \$ 400$ to be given as prepayment. She has the welfare. But with this money I buy the things for her to eat. That juice she drinks, the only one that she drinks, costs almost $R \$ 5$ ! And the things that she eats I cannot take away. Then it is impossible for me to take $R \$ 400$ for the orthosis! That's hard! (Mother, E6, P. 11/13)

The lack of money generates anguish, as there are not enough resources for the treatment and support the child needs. The members give up their needs in favor of the child and make a quite great physical effort to do what is possible. Another type of suffering is to know what it would do the child good and what can't be offered:

What would help is having more money! Because then I could pay the equitherapy! I would also like to pay for the swimming classes! (Mother, E1, P.8)

If I had money to pay for swimming classes I would put him into hydrotherapy [...] my dream is to see him in the swimming pool! [...] he loves water! [...] People say that money is a curse. I say that not having money is what a curse is! (Mother, E4, P.4/6)

Moreover, there is another sad reality, which only makes the care more difficult and adversely affects the relations. It is to perceive that in the health institutions many professionals have financial motives. This factor is present even within the public health system, causing distrust and weakness in the ties:

I called her 'Doctor, it's happening this, that and other things' and she said 'Can you pay a consultation at (Hospital) 'And I could not, at this time my husband was unemployed! So I said 'But Doctor, it was your injection! 'and she said 'I medicate my patients as I know to medicate and now I cannot do anything' [...] She (the doctor) wanted that I paid her for a consultation to see him! And at that time I didn't have anything, not even health insurance! My husband was unemployed and I had 2 other small children! (Mother, E4, P.3)

He (the child) would have made a surgery to prolongate the hamstring. He would have firstly made one leg and after three months he would have made the other one. This doctor here wanted to make one at a time because of this (she gestures money)! So he wanted to put my son into mistreatment! (Mother, E3, P.8).

\section{Discussion}

The results of this research point out that the chronic condition of the child influences and interfere with the family dynamics. In the established interaction with the child, each family member attributes meanings to the experiences, develops strategies and cares. The family starts to accept the condition of the child and its care is seen as work, with routines and duties. In spite of the position of confrontation that the family establishes for this situation, adversities and difficulties continue to occur, therefore the undergoing of the experience is neither a linear nor a static process, changing with elapsing time.

Data from literature corroborate with the ones of this study, when they point out that the family members spend much more time involved in medical activities than in the ones of leisure ${ }^{(8)}$, thus the treatment of health has an important dimension in the family life ${ }^{(7)}$ and the core of the concerns is concentrated on the future of the child(16). This picture increases the stress for the members and might be a factor for family conflict ${ }^{(8-9)}$.

The social inequalities and the poverty are dynamic and multidimensional phenomena that can interfere with the health of the individuals. The financial sphere has great impact on the confrontation of the chronicity. Literature, as well as information of these participants, indicate that children with chronic health condition demand higher familiar financial investment since the same imposes on the person a range of necessities that involve financial cost. The materials and resources for the child are expensive and add to the difficulty of the family members in keeping a job due to the necessary time for taking care of the child. Children need diverse health services, additional treatments and support materials. The medical expenses for children with a chronic condition are three times higher than in the case of healthy children. This impact is reported by the family: about $40 \%$ of the family expenses are increased due to the condition of the child( ${ }^{(9)}$. Thus, the cost of the treatment is a significant concern and for a long term, increasing the stress levels of the parents ${ }^{(9,18-19)}$.

Brazil is not a poor country, but a country of inequalities, with a high income concentration. The high levels of social vulnerability interfere with the full access to health(20). For the confrontation of adverse conditions the identification and definition of the real needs, difficulties in the access and conditions for making public actions regarding the promotion of health for the population feasible become necessary.

A bigger challenge is imposed on those who, besides living under financially unfavorable conditions, face the chronicity. The family members, aiming at one better life quality for their child, relentlessly search for resources and strategies. They place the interest of the child in first place and face difficulties to access the products and services. 
The bureaucracy and the lack of clarification permeate this process in a form that the family needs to discover the way. The fatigue provoked in the family by this disarticulation is emphasized in literature as function of low resilience in the system ${ }^{(21-22)}$. Moreover, the social vulnerability brings, many times, a stigma, a negative connotation for the society, associated to laziness and dependence.

The cerebral paralysis also links the stigma that people with cognitive incapacities are considered by a great part of the population as vulnerable and incapable of autonomy. And thus, the individuals are not always valued and have their individuality disrespected. Such fact is explicit in the usual solitude and the isolation lived by people with deficiencies, deriving from the restricted social relationship or inefficient support networks ${ }^{(9,18,20)}$. Unfortunately, as signalized in this study, this preconception is perceived in the relations established with individuals beyond the family circle.

Such a fact is also noticed in the relation with some health professionals, who sometimes, beyond offering a service of low quality, disrespect the decision power of the involved people(20,23). The disjointed actions of professionals and health programs do not contemplate an integral attention of the family needs. It becomes necessary to promote a complete and decisive care that exceeds the actions focused on exclusively in pathology.

When equating the procedures to the effective care of the family demands, the nurse provides a intercessory relation with the individual, based on shelter, bond and effective listening. Thus, we consider that the relation with the professionals, however, may diminish the impact of the social vulnerability, since the quality of the care and the support network can help to reduce the interference that the financial problems cause regarding the assistance. Studies point out that providing care coordinated with the services and considering the family as partner allow to increase the care offered to the child $^{(9,19,23)}$. Thus, the care must be provided by means of strategies that are directed to the real necessities of the family(21,24).

\section{Conclusion}

In this study, it was to observe that the chronic illness in a child, especially the cerebral paralysis, has great impact on the family that mobilizes, reorganizes itself and creates confrontation strategies. The investment in the necessities of the child, listed as priority, and the care time destined to it, interfere with the labor activity of at least one of the family members. In a situation of social vulnerability, the involved financial factor in the treatment of the child arises as source of concern and anguish. The involved costs are high and the public system does cannot fulfill all the demands. The family lists the necessities and fights daily in search of the best for their child. They face preconception barriers where they suffer on seeing the ignorance of people who do not understand and respect the faced condition, beyond the physical barriers of inadequate structures. They suffer and exhaust physically with the transport of the child, but the limited financial resources are invested in other as priority listed areas.

The health professionals and the strategies of public health are a great power and a privileged area to diminish the impact on the family difficulties, also the ones related to the family budget, but it was observed that they are not effective. Such reality demands that the professionals are sensitized to become resources of support for the family in the confrontation of the difficulties, to provide information, to offer and to guide the access to the available support networks and to spur the social service in action when necessary.

This study adds knowledge to the already existing by pointing out peculiarities of the family experience in situations regarding two variables of difficult handling: chronicity and social vulnerability, evidencing the role of the professional in search of the solution for the confrontation of demands and sufferings together with the family. The accomplishment of this research allows to visualize gaps of the knowledge in the scope of nursing and emphasizes with respect to future research that this can be developed by trying to approach the following demands: the handling of the preconception involved in the social vulnerability, the economic organization of the family in the day to day care of the child with cerebral paralysis, the communication between the family and the health aiming at the support resources.

It is salient that the health professionals need to work in a way to make the systems of reference and contrareference function efficiently, so that the care offered to the child is a promoter for growth, development, rehabilitation and continuous accompaniment, safe and efficient, what benefits the child and comforts the family, over-active participant in this process.

\section{References}

1. Parkes J, McCullough N, Madden A, McCahey E. The health of children with cerebral palsy and stress in their parents. J Adv Nurs. 2009;65(11):2311-23. 
2. Svedberg LE, Englund E, Malker $H$, Stener-Victorin

E. Comparison of impact on mood, health, and daily living experiences of primary caregivers of walking and non-walking children with cerebral palsy and provided community services support. European J Paediatr Neurol. 2010;14(3):239-46.

3. Dolk H, Parkes J, Hill N. Trends in prevalence of cerebral palys in Northern Ireland, 1981-1997. Develop Med Child Neurol. 2006;48:406-12.

4. Hemming $K$, Hutton $J L$, Cover $A$, Platt $M J$. Regional variation in the survival of people with cerebral palsy in the United Kingdom. Pediatrics. 2005;16(6):1383-90.

5. Mancini MC, Fiúza PM, Rebelo JM, Magalhães LC, Coelho ZAC, Paixão ML, et al. Comparação do desempenho de atividades funcionais em crianças com desenvolvimento normal e crianças com paralisia cerebral. Arq Neuropsiquiatr. 2002;60(2-B):446-52.

6. Marcon SS, Radovanovic CAT, Waidman MAP, Oliveira MLF. Life experience and reflections from a study group on families facing chronic health situation. Texto \& Contexto-Enferm. 2005;14:116-24.

7. Vieira MA, Lima RAG. Children and adolescents with a chronic disease: living with changes. . Rev. Latino-Am. Enfermagem. 2002;10(4):552-60.

8. Herzer M, Godiwala NBS, Hommel KA, Driscoll $K$, Mitchell M, Crosby LE, et al. Family functioning in the context of pediatric chronic conditions. J Develop Behavior Pediatrics. 2010;31(1):26-34.

9. Looman WS, O'Conner-Von SK, Ferski GJ, Hildenbrand DA. Financial and employment problems in families of children with special health care needs: implications for research and practice. J Pediatr Healthcare. 2009;23(2):117-25.

10. Wang C, Guttmann A, Dick PT. Neighborhood income and health outcomes in infants: how do those with complex chronic conditions fare? Archiv Pediatrics Adolesc Med. 2009;163(7):608-15.

11. Rose SM, Hatzenbuehler S. Embodying social class: the link between poverty, income inequality and health. Intern Soc Work. 2009;52(4):459-71.

12. Nikiema B, Spencer N, Seguin L. Poverty and chronic illness in early childhood: a comparison between the United Kingdom and Quebec. Pediatrics. 2010;125(3):499-507.

13. Instituto Brasileiro de Geografia e Estatística. Diretoria de Pesquisas, Coordenação de Trabalho e Rendimento. PNAD - Pesquisa Nacional por Amostra de Domicílios. Brasilia; 2011.
14. Fundação Sistema Estadual de Análise de Dados (BR). Índice Paulista de Vulnerabilidade Social. [acesso 29 jan 2011]. Disponível em: http://www.seade.gov.br/ projetos/ipvs/apresentacao.php

15. Blumer $H$. Symbolic interacionism: perspective and method. Berkeley: Berkeley, CA: University of California Press; 1969.

16. Turaro ER. Tratado da metodologia da pesquisa clínico-qualitativa. 4ed. Vozes: Petrópolis; 2010. 685 p.

17. Bardin L. Análise de conteúdo. Lisboa: Edições 70; 2006.

18. Buran CF, Sawin K, Grayson P, Criss S. Family needs assessment in cerebral palsy clinic. J Specialists Pediatr Nurs. 2009;14(2):86-93.

19. Whittingham K, Wee D, Boyd R. Systematic review of the efficacy of parenting interventions for children with cerebral palsy: Child Care Health Develop. $2011 ; 37(4): 475-83$.

20. Lustig DC, Strauser DR. Causal relationships between poverty and disability. Rehab Counsel Bull. 2007;50(4):194-202.

21. Moraes JRMM, Cabral IE. The social network of children with special healthcare needs in the (in) visibility of nursing care. Rev. Latino-Am. Enfermagem. 2012;20(2):282-8.

22. Oliveira BRG, Collet N, Mello DF, Lima RAG. The therapeutic journey of families of children with respiratory diseases in the public health service. Rev. Latino-Am. Enfermagem. 2012;20(3):453-61.

23. Mello DF, Lima RAG, Scochi CGS. Health follow-up of children in poverty situation: between the routine and eventuality of daily care. Rev. Latino-Am. Enfermagem. 2007;15(spec number):820-7.

24. Oliveira SHS, Monteiro MAA, Lopes MSV, Brito DMS de, Vieira NFC, Barroso MGT. Strategies to combat poverty and their interface with health promotion. Rev. Latino-Am. Enfermagem. 2007;15:867-73. 